\title{
Derivaciones de la ley 13.010: los derechos políticos de la mujer en las provincias ${ }^{1}$
}

\author{
Carolina Barry ${ }^{2}$
}

\section{Resumen}

Entre 1947 y 1951, el gobierno de Perón produjo un movimiento reformista que implementó un conjunto de instrumentos legales mediante los cuales se modificaron radicalmente los mecanismos y lasprácticas electorales. Uno de ellos fue la ley 13.010 de derechos políticos de la mujer. Una vez sancionada, y para que sus fines no se desvirtuaran, fue preciso contar con una legislación semejante en las provincias, en un momento en que el derecho a voto no tenía recepción constitucional a escala nacional, lo que les brindaría a aquellas un margen amplio de acción, ya fuera a través de sus normas o de sus constituciones. Este artículo sintetizaeste proceso de derivaciones y adaptaciones provinciales de la ley de voto femenino.

\section{Palabras clave}

Argentina - Ley 13.010 - Reformas electorales - Peronismo - Legislación provincial

\begin{abstract}
Summary
Between 1947 and 1951, Peron's government produced a reforms movement that implemented a set of legal instruments by which radically changed the mechanisms and electoral practices. One of them was the law 13,010 which allow women to vote and be elected. Once sanctioned, and their purposes not spoil, it was necessary to have such legislation in the provinces, when the right to vote had no constitutional nation wide reception. This situation would give them a wide margin of action, eith erthrough their rules or their constitutions. This articles ummarizes the process of derivations and adaptations of thelaw of Suffrage in the provinces.
\end{abstract}

\section{Keywords}

Argentina - Law 13,010 - Electoral reforms - Peronism - Provincial legislation

\section{Introducción}

La evolución de las luchas que tuvieron lugar en la Argentina para extender la ciudadanía política a las mujeres es análoga al dilatado y

\footnotetext{
${ }^{1}$ Trabajo recibido el 31/03/2016. Aceptado el 20/06/2016.

${ }^{2}$ Licenciada y Doctora en Ciencia Politica- Investigadora independiente del Consejo Nacional de Investigaciones Científicas y Técnicas. Profesora e investigadora en la Universidad Nacional Tres de Febrero. Directora del Programa de Estudios de Historia del Peronismo. Contacto: cbarry@fibertel.com.ar
} 
espinoso proceso que se registraba al mismo tiempo en otros países del mundo, proceso que se había iniciado a fines del siglo XIX y culminó casi un siglo después. Esta demanda había nacido en Estados Unidos e Inglaterra y en Latinoamérica fue seguida e impulsada por feministas y sufragistas como parte de un movimiento mundial por la emancipación de la mujer e Implicaba nada menos que un cuestionamiento al aparato legal sobre el que se basaban todas las actividades sociales y económicas. Una de las posibilidades de cambio sería por medio de la legislación y, más específicamente, en los modos de pensar los papeles del hombre y mujer en la sociedad. Por tratarse de un proceso político, requería, a su vez, de un arma política para su reconfiguración: el voto. El cambio que asentaba la legislación era ingente. El primer país de América Latina en otorgar el sufragio femenino fue Ecuador en 1929 y el último, Paraguay en 1961. No hubo grandes diferencias en el pensamiento opuesto al sufragio femenino a lo largo de toda Latinoamérica. La situación en el resto de los países no fue diferente, lo que otorga un marco referencial a la ampliación de ciudadanía femenina que se estaba gestando en el mundo. A modo de ejemplo, en 1947 Argentina, Venezuela y China sancionaron sus propias leyes de sufragio femenino. Un año antes lo habían hecho Trinidad y Tobago, Italia y Japón y, un año después, Corea del Sur e Israel. Es decir, la situación que transitaba América Latina no era en ningún modo excepcional, sino que formaba parte y se asentaba en un proceso general que atravesaba a gran parte de los países del mundo. ${ }^{3}$

La ley de sufragio asumió la forma de una apuesta a favor del armado de un cuerpo político y electoral nuevo, que implicaba la mutación de las mujeres en votantes y potenciales candidatas electivas. De esta manera se avanzó un paso en la universalización del sufragio, un concepto cuyo alcance se fue transformandoa lo largo de los años, que confesaba diferentes connotaciones y alcances de los que conocemos hoy en día. ${ }^{4} \mathrm{Al}$ iniciarse la experiencia de la república democrática, la dirigencia política se cuestionó la incongruencia resultante de la exclusión política de la mujer. En la Argentina, aunque fueron varios los proyectos parlamentarios presentados para reparar esta discriminación jurídica, ninguno, ni los que planteaban una integración parcial ni aquellos que proponían igualdad de derechos entre los hombres y las mujeres, llegó a aprobarse. ${ }^{5}$

\footnotetext{
${ }^{3}$ Barry, (2011):12.

${ }^{4}$ Ternavasio, (2002).

${ }^{5}$ Palermo, (2011): 29.
} 
Entre 1947 y 1951, el gobierno de Perón implementó un conjunto de instrumentos legales que permitió modificar radicalmente tanto los mecanismos como el sentido de las prácticas electorales dentro del sistema político. El sufragio femenino en 1947, la reforma de la Constitución en 1949, la ley 13.645 de Reglamentación delos Partidos Políticos de 1949 y la extensión de los derechos a los habitantes de los territorios nacionales, cuando no su provincialización, y la Ley Electoral 14.032 de 1951 fueron herramientas de este cambio. ${ }^{6}$ Luego de la sanción de la ley $13.010 y$ de la primera elección en que votaran las mujeres, el 11 de noviembre de 1951, seinstrumentó un continumm de leyes relacionadas con los derechos políticos femeninos, acaso el más significativo de la historia argentina. De esta manera, se reguló su participación electoral. Las dos derivaciones primeras y principales de la ley de voto femeninofueron: 1) las adecuaciones provinciales a fin de no desvirtuar el espíritu de ley nacional en las catorce provincias (los territorios nacionales se regían por otros canales normativos); 2) el enrolamiento, el empadronamiento y la documentación de las mujeres, un proceso cuyas razones remitían a la ley Sáenz Peña yque había que iniciar de cero. Sin entrar en disquisiciones sobre la ciudadanía de la cual dan cuenta otros trabajos, es preciso aclarar que ambos procesos, adecuación y enrolamiento, se condicionaron e interrelacionaron mutuamente al punto en que no podía existir el uno sin el otro.

Este trabajo forma parte de una saga de estudios referentes a la participación política de la mujer. Una investigación previa abordó lastransformaciones, luchas y procesos políticos latinoamericanos que se gestaron en torno asus derechos políticos. En él se puso el foco en la Argentina y se analizaron las principales fuerzas políticas y confesionales al momento de sancionarse la ley 13.010 en 1947. ${ }^{7}$ Otros importantes abordajes dieron cuenta de los tempranos debates legislativos en torno a la ley de voto ${ }^{8}$ de las principales propulsoras de los movimientos feministas y sufragistas ${ }^{9}$ y de las otras fuerzas políticas opositoras al peronismo. ${ }^{10}$ Este artículo pretende dar cuenta de cómo las provincias resolvieron su propia normativa en torno a la ley de sufragio femenino, una reforma electoral que ampliaba considerablemente al electorado

\footnotetext{
${ }^{6}$ De Privitellio, (2011): 216.

${ }^{7}$ Barry, (2011).

${ }^{8}$ Palermo, (2012).

${ }^{9}$ Barrancos, (2007).

${ }^{10}$ Valobra, (2010).
} 
activo. El cuadro que se observa a priori es que no se dieron situaciones uniformes y que existieron debates tempranos y anteriores a la ley nacional y, otros, en concomitancia con ella. No se puede aislar esta normativa del proceso legislativo y administrativo simultáneo de enrolamiento femenino, pero éste es el tema de otro trabajo en curso. Las adecuaciones provinciales a la ley 13.010 es un asunto que ha sido descuidado y prácticamente no abordado por la historiografía, quizás por la enorme dificultad de acceso a las fuentes básicas. Hay que tener en cuenta que no existen anales de legislación por provincias y que, en general, los archivos de la legislación se encuentran dispersos y se depende de la buena voluntad de quienes manejan los reservorios. En ese sentido, quiero agradecer a la Dirección de Servicios Legislativos de la Nación, a los archivos de las legislaturas provinciales de San Luis, Córdoba, San Juan, Entre Ríos y Buenos Aires. También a José María Pérez Corti. A Cristina Nacif, Adriana Kindgard y María del Mar Solís por su ayuda con la legislación en San Juan, Jujuy y Corrientes. Sobre algunos distritos no se ha podido acceder a ningún tipo de información.

\section{El régimen de sufragio}

El régimen del sufragio no tenía recepción constitucional a escala nacional y, por lo tanto, permitía a las provincias un amplísimo y discrecional margen de regulación al respecto, ya fuera a través de sus normas o de sus constituciones. Dicho proceso no fue ni uniforme ni sistemático ni ordenado, sino que simplemente fue sucediendo de manera gradual. No todas las provincias tuvieron el mismo comportamiento y no necesariamente formalizaron el sufragio femenino a través del dictado de normas explícitas. ${ }^{11}$ Este derecho se incorporó en la Constitución Nacional recién en la reforma de 1994, en su artículo 37. El proceso constitucional federal argentino se extendió significativamente en el tiempo y la regulación del derecho de sufragio fue objeto de un proceso gradual, lo cual no impidió que las provincias lo fueran normalizando en sus propios ordenamientos durante el transcurso del proceso de constitucionalización. La Constitución garantiza a las provincias el establecimiento de sus instituciones y la elección de sus autoridades sin intervención del gobierno federal; a su vez, éstas tienen el derecho de establecer un régi-

${ }^{11}$ Entrevista de la autora con José María Pérez Corti, Córdoba-Buenos Aires, 12/05/2014. 
men electoral propio, como también lo tienen en materia de partidos políticos y en relación con la facultad de establecer su sistema de elecciones.

Luego de la sanción de la ley Sáenz Peña, fue necesaria una adecuación de las leyes provinciales a la nueva situación planteada, aunque las experiencias en algunas provincias habían anticipado lo que en el orden nacional fue presentado como una novedad. ${ }^{12}$ Una situación equivalente se planteó con la ley 13.010: cuando se aprobó con bombos y platillos había provincias que ya contaban con su propia normativa y donde el tema ya estaba instalado desde tiempo atrás. La asociación unánime de Eva Perón con la ley, aceptada por propios y ajenos y luego trasladada a la investigación de alguna manera obturó esos resquicios que conducen al estudio de las situaciones en las distintas provincias.

A los pocos días de su promulgación, el gobierno planteó la necesidad de que las provincias adecuasen sus propias leyes electorales a fin de no desvirtuar la normativa que sancionaba el sufragio femenino. Esto a riesgo de que pudiera darse el caso en que una mujer pudiera votar a presidente o vicepresidente y diputados y senadores nacionales y no pudiera hacerlo para la designación de gobernador y legisladores provinciales. O de que pudiera ser elegida diputada pero no representante de su propio distrito en la legislatura oser presidenta de la república pero no gobernadora. Es más, al momento de la sanción de la ley la constitución estipulaba que el voto indirecto para senadores nacionales se daba a través de la legislatura, lo cual implicaba que, en el caso de que no existieran las leyes provinciales, las mujeres no podrían participar de esa elección. Además, de no realizarse una modificación, los senadores nacionales solamente serían votados por los hombres, que eran los únicos que intervenían en la formación de las legislaturas, salvo en San Juan, provincia que ya contaba con su propia ley. Se planteó entonces como perentoria la necesidad de contar con mecanismos legales que no desvirtuaran elespíritu de la ley de voto femenino.

El tema se tornó acuciante y correspondió a Eva Perón encabezar una nueva cruzada para lograr que los gobernadores y dirigentes provinciales del peronismo se comprometieran a hacerlo con la sanción de una ley provincial. ${ }^{13}$ El periódico Democracia también comenzó una campaña

${ }^{12}$ Ferrari, (2012): 183-304.

${ }^{13}$ Democracia, Buenos Aires, 21/09/1947. 
para presionarlos a un rápido tratamiento de la ley de sufragio. ${ }^{14}$ Algunas experiencias muestran que el tema ya estaba instalado en el clima de la época y que las provincias lo resolvieron de distintas maneras. Su desarrollo temporal podría dividirse en tres etapas: a) la anterior a la ley 13.010;b) la inmediatamente posterior; y c) y una tercera, de «último momento». Pero también dentro de este intento de sistematización se observan variables muy marcadas, de las que se dará cuenta a continuación.

\section{San Juan, la pionera}

San Juan perdura como la provincia pionera en la legislación de derechos femeninos y es la más mencionada por los legisladores que intervinieron en el debate nacional como el ejemplo a seguir. ${ }^{15} \mathrm{La}$ ventaja de esta provincia se remonta al siglo XIX, puesto que la constitución provincial de 1856 establecía al cabildo como un gobierno municipal autónomo en cada departamento, administrado por los contribuyentes, sin distinción de nacionalidad o sexo. Veinte años antes de la ley 13.010,la Constitución de 1927confirió, en su artículo 34, el mismo derecho y el deber de votar a los argentinos nativos o naturalizados, de uno u otro sexo, residentes en la provincia y mayores de dieciocho años. ${ }^{16}$ Incluso los miembros de las municipalidades podían ser elegidos directamente por el voto de los electores de ambos sexos, nacionales o extranjeros, mayores de 18 años (artículo 140). Entre sus fundamentos aducía la tradición democrática de los países más adelantados del mundo, como Alemania, Estados Unidos, Australia, Suecia e Inglaterra, entre otros. Este proyecto, original del socialismo aunque no reconocido como antecedente, fue adoptado por la Unión Cívica Radical Bloquista. Esta ley posibilitó quelas mujeres votasen por primera vez en la elección del 8 de abril de 1928 para concejales y diputados provinciales. ${ }^{17} \mathrm{La}$ intervención elimina a las ciudadanas del padrón y en 1931 se produjeron intentos de retrotraer a las mujeres al condición de menores de edad al pretender derogarse los derechos civiles de $1926 .{ }^{18}$ Por esta razón, en la campaña

\footnotetext{
${ }^{14}$ Democracia, Buenos Aires, 19/09/1947.

${ }^{15}$ La Reforma, San Juan, 24/10/1947.

${ }^{16}$ Ramella, (1981): 125 y ss.

${ }^{17}$ Guzmán Páez, (1996).

18 Bianchi, (1986):250.
} 
electoral para las elecciones del 24 de febrero de 1946 existió un especial interés por captar el voto femenino. Un nutrido grupo de mujeres laboristas acudió a la provincia para ayudar en el otorgamiento de las libretas cívicas y para organizar el recibimiento a Perón en el contexto de la campaña electoral. Aunque seguiría latente un antecedente que podía dar lugar a que ellas votaran:en 1931, Cantoni había ganado sin la participación de las mujeres, pero llamó a otra elección incluyéndolas y obtuvo un margen mucho más amplio. Ese precedente fue mencionado recurrentemente por la prensa durante la campaña electoral de $1946 .{ }^{19}$ Pero la falta de actualizaciones en el empadronamiento y cuestiones de tipo político dieron por tierra con esta posibilidad. El decreto 2.380 del 14 de diciembre de 1945 estableció que en esa elección provincial solo deberían ser convocados los electores varones, con prescindencia del voto femenino. ${ }^{20}$ Al votarse la ley 13.010, no fueron necesarias nuevas modificaciones legales, sino que se mantuvieron las leyes vigentes en ese momento.

\section{Otras consideraciones constitucionales}

Santa Fe (1921), Entre Ríos (1933) y Buenos Aires (1934) tuvieron también sus consideraciones constitucionales en forma previa a la ley 13.010. En Santa Fe, el sufragio femenino con alcance municipal estuvo contemplado en la reforma total de la Constitución de 1921 a instancias del demócrata progresista Antonio F. Cafferata: el artículo 144 otorgaba el derecho a elegir y a ser elegidos a mujeres y extranjeros que tuvieran 22 años de edad y que supieran leer y escribir. También lo sostenía la activa intervención del convencional socialista Luis Bonaparte. Esta reforma no llegó a aplicarse ante el veto del gobernador Enrique Mosca, aunque luego fue puesta en vigencia en 1932 hasta la intervención federal de 1935, en que se volvió al texto originario. ${ }^{21}$ La Ley Orgánica de Municipalidades ( $\mathrm{n}^{\circ} 2.147$ ) permitió que el 30 de abril de 1928 las santafecinas votaran por primera vez, además de hacer el voto extensivo a todos los varones, cuando antes solo estaban contemplados los contribuyentes. Respecto de las mujeres, solo podían votar las mayores de 22 años, contribuyentes con una cantidad mayor a $\$ 50$ por año y que poseyeran un título universitario que las acreditara para ejercer profe-

\footnotetext{
${ }^{19}$ Healey(2012): 365.

${ }^{20} \operatorname{Barry}(2014)$ : 12.

${ }^{21}$ Macor, (1994).
} 
siones liberales docentes o comerciales. El empadronamiento se resolvió con la confección de uno especial para mujeres y extranjeros. En esta primera elección votó solo el 40\% del padrón, lo que implicó la queja por la poca cantidad de mujeres inscriptas, de quienes se publicaban los nombres y ocupaciones. ${ }^{22}$ Esta ley solo se aplicaba a municipalidades, con lo cual, luego de la ley 13.010, el 17 de septiembre de 1948, la ley 3.394 incorporó modificaciones necesarias acordes con la ley nacional. ${ }^{23}$

La Constitución de Entre Ríos de 1933 estableció que el derecho de sufragio a la mujer, en el orden provincial o municipal o en ambos a la vez, podría ser otorgado por la Legislatura con carácter facultativo u obligatorio. Al igual que la constitución bonaerense de 1934, en su artículo 46 señalaba que la legislatura podría acordar el sufragio a la mujer argentina por dos tercios del total de los votos de la Cámara. Según observa Valobra, los derechos políticos femeninos no podrían quedar ligados a la reforma realizada durante los gobiernos conservadores. ${ }^{24}$

\section{La primera ley del peronismo}

Hasta aquí las normativas previas a la ley 13.010 y su adecuación posterior. Ahora bien, ya durante el periodo peronista, Jujuy se posicionó como la pionera: presentó un proyectoen la segunda sesión ordinaria de la Cámara, el 28 de mayo de 1946, una semana antes de que Perón asumiera la presidencia de la Nación y dos meses antes deque entrara en el parlamento nacional el proyecto que derivaría en la leyl3.010. La ley 1.681 se aprobó el 29 de agosto de 1946, pero se acordó que entraría en vigencia una vez que el Congreso de la Nación sancionara una ley análoga para todo el país. ${ }^{25}$ Los legisladores Carlos Snopeck y Juan Rosalío Lozano presentaron el proyecto, aunque es probable que su autor haya sido Guillermo Snopeck, quien habitualmente los redactaba. Los hermanos Snopeck habían militado en las filas del radicalismo sabattinista,

\footnotetext{
${ }^{22}$ La falta de inscripciones provocó numerosas quejas que los diarios reflejaban con gusto para señalar el poco entusiasmo femenino. Quince días antes de la elección sólo se habían inscripto dos mujeres en Santa Fe y cinco en Rafaela, de las cuales votaron cuatro. Eran dos profesoras normales, dos modistas yuna maestra. El Orden, Santa Fe, 30/04/1928.

${ }^{23}$ La ley 3.394 adecuó las leyes 2.600 y su modificatoria 2.899 , y las leyes 2.349 y 2.756 y sus modificatorias.

${ }^{24}$ Valobra, (2013): 87.

${ }^{25}$ República Argentina,Anales de Legislación Argentina, La Ley, Buenos Aires, 1948, BO 08/06/1948.
} 
un paso típico de los estudiantes tanquistas radicados en Córdoba durante sus estudios universitarios. Guillermo fue un jurista importante, a quien se debe la redacción del nuevo código civil de Jujuy, de diversas leyes laborales y de la constitución provincial de $1949 .{ }^{26}$

Los tanquistas, luego devenidos en renovadores dentro del naciente peronismo, propugnaban desde la década del treinta el reconocimiento de los derechos políticos de la mujer. Los fundamentos del proyecto de Snopeck retomaban muchos de los planteos ofrecidos por el senador socialista Mario Bravo en 1929, quien había presentado el primer proyecto que reconocíalos derechos políticos a las mujeres de la misma manera que a los hombres. ${ }^{27} \mathrm{El}$ eje central de ambos fundamentos estribaba en el exceso de atribuciones del Congreso en sus facultades reglamentarias, que incluso traspasaban las normas constitucionales respecto de los derechos políticos de la mujer. De allí que las leyes electorales contrariaron los principios constitucionales de igualdad que establece la Constitución. ${ }^{28}$ Sustentaba sus argumentos en las mismas profusas citas sobre John Stuart Mill y no remitían a innecesarias justificaciones externas como haber participado en guerras mundiales ni a una defensa empalagosa tal como la que empezó a observarse durante los debates de la ley 13.010 y sus adaptaciones.La fundamentación era netamente jurídicay se asentaba en los instrumentos constitucionales nacionales y provinciales vigentes, suficientes para que la mujer pudiera votar. Acusaba al Congreso Nacional, en ejercicio de sus facultades reglamentarias, de haberse excedido al establecer los límites de la capacidad política. Esta ley no era modificatoria de la ley electoral de la provincia, sino interpretativa o aclaratoria, por cuanto completaba el sentido y verdaderoalcance al consagrar que las mujeres tenían el derecho y la obligación de cumplir con el sufragio como ciudadanas argentinas. Aducía, además, que la Constitución Nacional y provincial no hacía una disquisición entre sexos; y quela ley de ciudadanía vigente «que no daba cuenta de una división entre varones y mujeres» englobaba a ambos en el mismo concepto. En su fundamentación se valió de un fallo de la Justicia Federal y de la Corte Suprema de Justicia Nacional y las recientemente firmadas actas de Chapultepec. $^{29}$

\footnotetext{
${ }^{26}$ Kindgard, (2010).

${ }^{27}$ CN, DSCS, Sesión ordinaria, 25/09/1929. En Palermo, (2012): 44-57.

${ }^{28}$ CN, DSCS, Sesión ordinaria, 25/09/1929. En Palermo, (2012): 54.

${ }^{29}$ AHLP, Diario de Sesiones de la Legislatura Provincial, Jujuy, 28/05/1946, pp. 43-47.
} 
Las posturas no eran homogéneas y la disidencia se planteó dentro del escueto debate que provino de las mismas filas políticas: el diputado Andrés Rivas, proveniente del tanquismo de la «primera hora», dijo ser contrario al sufragio femenino en el país. Su argumento rondaba en las diferencias de orden sociológico entre ambos sexos e incluso señaló que la ciudadanía masculina había demostrado de por sí ser suficientemente hábil para ejercer «ese sagrado derecho [...] que llevó a la primera magistratura del país un ciudadano virtuoso y democrático, cual el general Perón ${ }^{30}$ y, además, que podría desvirtuar su carácter de ama de casa y su femineidad. Pese a su oposición a que el «vendaval lleve sus flores al viento», votó a favor de la ley por solidaridad con su banca y porque se encontraba inserto en el Acta de Chapultepec. El periódico jujeño Crónica dio cuenta de estos debates con una extraña justificación, basada en el coraje que habían demostrado las mujeres en las dos guerras y sobre todo en los patéticos (sic) días vividos en Londres, cuando los ingleses fueron atacados por la aviación alemana. ${ }^{31}$ La mirada estaba puesta en las europeas y no en la realidad provincial, como la coya que por esos días participaba del Malón de Paz que tenía convulsionado a Buenos Aires. ${ }^{32}$ Luego de sancionada la ley 13.010, en 1948, se adecuó el articulado sobre la formación de registros electorales. Y la reforma de la constitución provincial de 1949 subrayó que los electores de la provincia estaban integrados por ambos sexos.

\section{La ley que no fue}

Casi en simultáneo con los jujeños, el 11 de junio 1946, Eduardo Martínez Carranza, del Partido Demócrata Nacional de Córdoba, presentó un proyecto para modificar la ley electoral 3.365 del año 1925, ${ }^{33}$ en el quese establecía que la edad de voto para los varones se mantuviera en dieciocho años y que para las mujeres fuese a partir de los veintidós, pudiendo solo ser electoras y no candidatas a un cargo electivo. ${ }^{34} \mathrm{La}$ fundamentación de la edad estaba dadapor ser la misma que el Código otor-

\footnotetext{
${ }^{30}$ AHLP, Diario de Sesiones de la Legislatura Provincial, Jujuy, 22/08/1946, pp. 467-469.

${ }^{31}$ Crónica, Jujuy, 22/08/1946.

32 Sobre este tema ver Kindgard, (2004).

${ }^{33} \mathrm{El}$ proyecto modificaba parte del articulado de las leyes provinciales 3.365 y 3.371 que habían adaptado la ley nacional 8.871 .

${ }^{34}$ Roggio, (2013): 87.
} 
gaba a las personas para administrar los bienes personales. Los despachos de la mayoría, en la voz del diputado radical Wenceslao Cabral, propusieron igualar en edad a varones y mujeres. Cabral -sin mucha imaginación» alegó que los dieciocho años sería la edad adecuada puesto que ellas habían demostrado su capacidad en la Segunda Guerra Mundial, de la cual, de más está decir, las cordobesas no habían participado. Pero también objetaban la violación de los preceptos constitucionales sobre el alcance de la ciudadanía extendida para ambos sexos. ${ }^{35}$ Las disidencias a la hora de votar traspasaban los límites de lo partidario y se produjeron votaciones cruzadas; por ejemplo, el presidente del bloque oficialista votó el proyecto original con los diputados del Partido Demócrata. Los diputados peronistas, por su parte, hicieron propio el proyecto original y defendieron el despacho que había sido abandonado por el bloque demócrata. Francisco Cornavaca, radical, apoyó las posiciones conservadoras del peronismo, que salió con una rara conjunción partidaria. Radicales, demócratas, laboristas y algunos peronistas apoyaron la versión más progresista. ${ }^{36} \mathrm{El}$ proyecto pasó al Senado de la provincia, donde los conflictos imperantes entre este cuerpo y el gobierno de la provincia impidieron su tratamiento.

Córdoba no contó con una ley propia; sin embargo,estaba amparada por la constitución provincial de 1949, donde el pueblo era elector, aunque no hacía referencia específica a las mujeres, como sí se señaló en otros textos constitucionales contemporáneos de otras provincias. ${ }^{37} \mathrm{Y}$ a su vez, la ley 4.292 del 19 de agosto de 1951 refrendaba la ley nacional 14.032, que señalaba que el cuerpo electoral de la nación estaba constituido sin distinción de sexos por argentinos nativos y por opción mayores de 18 años de edad.

\section{Otra cruzada de Eva Perón}

Luego de la aprobación de la ley 13.010, y del llamado urgente de Eva Perón a adecuar las legislaciones provinciales, San Luis tomó la delantera en varios sentidos. Fue la primera en sancionar su propia normativa y el 31 de octubre de 1947 se promulgó la ley 1.988 de Derechos

\footnotetext{
${ }^{35}$ Cámara de Diputado de la provincia de Córdoba, Diario de Sesiones, 11/09/1946, p. 1432 .

${ }^{36}$ Tcach, (2014):42.

${ }^{37}$ Tcach y Philp (2010).
} 
Políticos de la Mujer. Sin embargo, en su artículo 4 se señalaba que la normativa entraría en vigencia en el año 1950, siempre y cuando para esa fecha rigiese la ley $13.010 .{ }^{38} \mathrm{El}$ proyecto había sido presentado por el diputado peronista Sixto Alberto Laserna ysus fundamentos consistían en los mismos puntos quehabían estipulado en la temprana ley jujeña. Allí se señalaba que ni la Constitución Nacional ni la provincial excluían a la mujer de intervenir en la vida pública de la nación o de la provincia. Sin embargo, el autor, cultivando el espíritu de época «aunque sin remitir a las guerras mundiales», estrenó dos nuevos argumentos. El primero sostenía que la mujer merecía los derechos políticos por su participación en el 17 de octubre como garantía para la democracia por «haber luchado codo a codo para salvar al país de la oligarquía». El segundo radicaba en que se trataba de una de las aspiraciones de la revolución y de su «más destacada intérprete la primera dama argentina señora María Eva Duarte de Perón». ${ }^{39}$ Éste fue el único proyecto cuyos fundamentos hacían este tipo de referencias, que luego serían la moneda corriente adoptada por los distintos sectores del peronismo.

La Rioja siguió en el orden con la sanción de la ley 1.115, que modificaba la ley electoral provincial 788 que otorgaba el voto a varones y mujeres desde los dieciocho años de edad, siempre que estuvieran inscriptos en el registro cívico. ${ }^{40}$ Luego, Buenos Aires, de la mano del presto gobernador Mercante, se hizo eco del llamado de Eva Perón y dio un fuerte impulso al proyecto presentado por el diputado César Bressa. ${ }^{41}$ El 30 de octubre de 1947 se sancionó bajo el número 5.241..$^{42}$ Esta ley de la provincia deBuenos Aires modificó su novel estatuto electoral 5.109 (del 9 de noviembre de 1946), que nada decía sobre las mujeres.

En mayo de 1948, Tucumán -con la ley 2.166- modificó el artículo $1^{\mathrm{O}}$ de la ley electoral de la provincia acordando el voto a la mujer y derogó toda disposición que se opusiera al cumplimiento de esta ley de sufragio femenino. ${ }^{43} \mathrm{El}$ voto fue unánime. El proyecto había sido presen-

\footnotetext{
${ }^{38}$ RA,Anales de Legislación Argentina, La Ley, Buenos Aires, 1947, BO 06/11/1947, sanción 22/10/1947, promulgación 31/10/1947.

${ }^{39}$ Legislatura de San Luis, Ley 1988, Legajo. 1947.

${ }^{40}$ RA,Anales de Legislación Argentina, La Ley, Buenos Aires, 1947, BO 28/10/47, sanción 08/10/1947, promulgación 10/10/1947.

${ }^{41}$ Valobra, (2013):87.

${ }^{42}$ RA,Anales de Legislación Argentina, La Ley, Buenos Aries, 1947, 13/11/1947, BO $17 /$ $12 / 1947$.

${ }^{43}$ RA,Anales de Legislación Argentina. La Ley, Buenos Aires, sanción 14/05/1948, promulgación 27/05/1948, BO 11/06/1948.
} 
tado por los legisladores Enrique Zarlengay Raimundo Bianco. En esta provincia se había propiciado el voto municipal sin éxito, tal como lo denunciara el diputado radical Guillermo Curia. ${ }^{44}$ No hubo mayores cuestionamientos, salvo del diputado José Francisco Chazal, proveniente de la vertiente conservadora Bandera Blanca, que propuso sin éxito que el voto no fuera obligatorio. Mientras tanto, en Salta la ley 919 además de las disposiciones comunes a todas estas leyes estableció que regiría para la primera elección provincial que se realizara, siempre que sesenta días antes se hubiese confeccionado el padrón electoral femenino de la Nación. ${ }^{45}$ Luego, la ley 2.262 del 16 de noviembre de 1949 sobre el régimen electoral en la provincia dispuso más taxativamente que los electores eran de ambos sexos.

Unos meses antes de las elecciones de 1951, la legislatura de Entre Ríos había aprobado la ley 3.703, por la que se extendían a la mujer los derechos, deberes y obligaciones cívicas consagrados para los ciudadanos argentinos por la Constitución de la provincia. Corrientes, que había estado intervenida entre 1947 y 1948, sancionó, el 5 de septiembre de 1951, la ley 1.623 de régimen electoral, donde también declaraba la constitución del cuerpo electoral sin distinción de sexos.

\section{Reflexiones finales}

Durante el primer gobierno de Perón se produjo la más profunda modificación electoral argentina. Una de ellas fue la ley de derechos políticos de la mujer, que se estrenó en la primera elección en que votaron las mujeres argentinas, el 11 de noviembre de 1951. Lo hicieron tanto las que vivían en provincias como en territorios nacionales. También fueron votadas en esta elección. Los mecanismos de aplicación y adecuación de la ley 13.010 fueron diferentes en todo el país. Aunque, cuando se aprobó, había provincias donde el tema ya estaba instalado y en otras, hasta legislado desde tiempo atrás.

Así como luego de la ley Sáenz Peña fue necesaria una adecuación de las leyes provinciales a la nueva situación legal, un escenario equivalente se planteó con la ley 13.010. No todas las provincias tuvieron el

\footnotetext{
${ }^{44}$ Provincia de Tucumán, Cámara de Diputados, Tucumán, 15/04/1948.

${ }^{45}$ RA,Anales de Legislación Argentina, La Ley, Buenos Aires, sanción 18/06/1948, promulgación 24/06/1948, BO 29/06/1948.
} 
mismo comportamiento normativo y no necesariamente formalizaron el sufragio femenino a través del dictado de normas explícitas.

Este artículo pretendió hacer un recorrido por las distintas situaciones provinciales, de acuerdo con las fuentes obtenidas hasta el momento, una suerte de puntapié inicial que conduzca a nuevos estudios. La adaptación de esta ley ha sido un proceso que se extendió significativamente en el tiempo, lo que no impidió que las provincias normalizaran sus propios ordenamientos y constituciones durante el transcurso del proceso de constitucionalización que culminó en 1994.

$\mathrm{Al}$ momento de sancionarse la 13.010 el sufragio no tenía recepción constitucional a nivel nacional y, por lo tanto, la regla federal electoral permitía a las provincias un margen amplio y discrecional de regulación, ya fuera a través de sus normas o de sus constituciones. Dicho proceso, como se ha visto, no fue ni parejo ni metódico ni sistemático; en algunos casos, estaba dado y, en otros, tuvo una clara instrucción del gobierno central. Las provincias no necesariamente formalizaron el sufragio femenino a través del dictado de normas explícitas. Simplemente, aplicaban sus normas políticas en un contexto en el que el sufragio era sinónimo de masculino y, luego, con la incorporación explícita del sufragio femenino a la normativa nacional.

A su vez, la ley 13.010 es el punto de inflexión que comienza a invertir el movimiento federal centrífugo ${ }^{46}$ en materia electoral y comienza a convertirlo en un movimiento centrípeto, al redireccionar contenidos del sufragio hacia la competencia nacional, que llegó al máximo punto en 1994, con su constitucionalización. En este sentido, en su artículo 37 , la norma señala:

«El sufragio es universal, igual, secreto y obligatorio y con igualdad real de oportunidades entre varones y mujeres para el acceso a cargos electivos y partidarios se garantizará por acciones positivas en la regulación de los partidos políticos y en el régimen electoral».

Esta aclaración precisa sobre «varones y mujeres» tuvo uno de sus antecedentes en las reformas de las constituciones de Corrientes, Mendoza y Jujuy, que declaraban en el articulado sobre el régimen electoral que no había distinción de sexos al momento del acceso a los derechos políticos. El resto de las once provincias refieren indistintamente al pue-

${ }^{46}$ Frías, (1980). 
blo o a los ciudadanos argentinos, pero sin hacer este tipo de aclaración. En 1951, al votarse la ley sobre régimen electoral, la 14.032, también se adoptó esta fórmula y se explicitó que el cuerpo electoral de la nación se conformaría sin distinción de sexos.

La legislación en los territorios nacionales corría por otros carriles. Cuando se promulgó la ley sobre régimen electoral, de los ocho territorios nacionales provincializados durante el gobierno de Perón, solo tres de ellos alcanzaron su autonomía institucional durante la década. Diferentes decretos presidenciales convocaron en 1951 a los chaqueños, en 1952 a los pampeanos y en 1954 a los misioneros a elegir quince convencionales constituyentes. ${ }^{47}$ En esas elecciones votaron tanto varones como mujeres y se adoptó como régimen electoral el vigente para el orden nacional.

La ley 13.010 tuvo ramificaciones políticas, legales y burocráticasque excedieron el derecho de las mujeres de votar y ser votadas. Por un lado, al prestar atención a quelas provincias estuvieran en consonancia con la nación; por otro, debido a la necesidad de proveer de documentación a las futuras votantes, que les permitiese, también, empadronarse y afiliarse. La ley electoral adjudica la potestad de votar a determinados individuos, que quedan investidos de la capacidad electoral. Sin embargo, el recaudo más prevalente ha sido la inscripción en el padrón electoral, un tema que aún queda por indagar.

\section{Bibliografía}

ARIAS BUCCIARELLI, Mario, (2009), «El peronismo clásico y los excluidos de la ley Sáenz Peña. Aportes para un debate desde los Territorios Nacionales». Avances del Cesor 6: 27-41.

BARRANCOS, Dora, (2007), Mujeres en la sociedad argentina. Una historia de cinco siglos. Buenos Aires: Sudamericana.

BARRY, Carolina, (2011) (dir.), El sufragio femenino. Prácticas y debates politicos, religiosos y culturales en Argentina y América Latina. Caseros: Eduntref.

BARRY, Carolina (2014), «De la Rama al Partido: leyes, militancias y liderazgos entre 1948-1949», [en línea], Revista Temas de Historia Argentina y Americana, Universidad Católica Argentina, 22.

${ }^{47}$ Arias Bucciarelli, (2009). 
BIANCHI, Susana (1986), «Peronismo y sufragio femenino: la ley electoral de 1947», Anuario IEHS, Tandil, UNCPBA, 1986, pp. 255296.

DE PRIVITELLIO, Luciano, (2011), «Las elecciones entre dos reformas: 1900-1955», en SÁBATO, Hilda-TERNAVASIO, MarcelaDE PRIVITELLIO, Luciano y PERSELLO, Ana Virginia. Historia de las elecciones en la Argentina 1805-2011. Buenos Aires: El Ateneo. pp. 135-213.

FERRARI, Marcela, (2012), «De la nación a las provincias. Adaptaciones de la ley Sáenz Peña», Estudios Sociales, Revista Universitaria Semestral XII (43): 183-304.

FRIAS, Pedro, (1987), Derecho público provincial. Buenos Aires: Depalma.

GUZMÁN PÁEZ, Laura, (1996), La participación activa de la mujer en politica. Formación del Partido Peronista Femenino en San Juan 19471955. Tesis de Licenciatura inédita. San Juan: Universidad Nacional de San Juan.

HEALEY, Mark, (2012), El peronismo entre las ruinas. El terremoto y la reconstrucción de San Juan. Buenos Aires: Siglo XXI.

KINDGARD, Adriana, (2004), «Tradición y conflicto social en los Andes argentinos: en torno al Malón de la paz de 1946», Estudios Interdisciplinarios de América Latina y El Caribe, Tel Aviv, vol. 15, $\mathrm{n}^{\mathrm{O}} \mathrm{l}$.

KINDGARD, Adriana, (2010), «Estado, partido y elecciones en Jujuy en tiempos del primer peronismo», en Oscar AELO (comp.), Las configuraciones provinciales del peronismo. Actores y prácticas politicas, 1945-1955. Buenos Aires: Instituto Cultural de la Provincia de Buenos Aires.

MACOR, Darío, (1994), La reforma politica en la encrucijada. La experiencia demoprogresista en el Estado provincial santafesino. Santa Fe:Universidad del Litoral.

TCACH, César, (2014), «Obreros rebeldes, sexo y religión en el origen del peronismo cordobés». En MACOR, Darío y César TCACH (eds.), La invención del peronismo en el interior del país I. Santa Fe: Universidad Nacional del Litoral.

PALERMO, Silvana, (2012), Los derechos politicos de la mujer. Los proyectos y debates parlamentarios 1916-1055.Los Polvorines: Universi- 
dad de General Sarmiento; Secretaría de Relaciones Parlamentarias-Jefatura de Gabinete de Ministros.

RAMELLA,Pablo, (1981), Las constituciones de San Juan. San Juan: Instituto de Derecho Público, Facultad de Derecho y Ciencias Sociales, Universidad Católica de Cuyo.

ROGGIO, Patricia, (2013), «Mujeres en la Córdoba peronista, 19461955», en Lucía RIBA y Eduardo MATTIO (eds.), Cuerpos, historicidad y religión. Reflexiones para una cultura postsecular. Córdoba: EDUCC.

TCACH, Cesar y PHILP, Marta (2010) «Estado y Partido Peronista en Córdoba: Una interpretación», enCésar TCACH (coord.), Córdoba Bicentenaria: claves de su historia contemporánea, Córdoba: Centro de Estudios Avanzados y Editorial de la Universidad Nacional de Córdoba.

TERNAVASIO, Marcela, (2002), La revolución del voto. Politica y elecciones en Buenos Aires, 1810-1852. Buenos Aires: Siglo XXI.

VALOBRA, Adriana, (2013), Acción politica y representación de las mujeres en la provincia de Buenos Aires, 1900-1955. La Plata: Instituto Cultural de la Provincia de Buenos Aires, Archivo Histórico «Dr. Ricardo Levene». 